\title{
Etoricoxib Induced Skin Rashes: Case Report
}

\author{
Syed Zia Inamdar ${ }^{*, 1}$, Rosy P Joseph², K Pradeepti², N Ashwini², Raghavendra V. Kulkarni ${ }^{1}$ \\ ${ }^{1}$ BLDEA's College of Pharmacy, Department of Pharmacy Practice Vijaypura, Karnataka, INDIA. \\ 'Intern, Pharm D, BLDEA's College of Pharmacy, Vijaypura, Karnataka, INDIA.
}

\begin{abstract}
Etoricoxib comes under the class Non-steroidal anti-inflammatory drugs (NSAIDS). It is a selective Cyclooxygenenase-2 enzyme inhibitor which is used mainly for its analgesic effects. Although it is highly efficacious in pain management, the safety profile of COX-2 inhibitor is yet not established in a broader sense. A patient admitted to the medicine ward of a tertiary care hospital with complaints of skin rashes over the face, trunk and extremities. The detailed history of present illness and past medical /medication history revealed the use of Etoricoxib by the patient for the past one month to treat his Rheumatoid Arthritis. it was suspected that the allergic reaction was caused due to the use of Etoricoxib. The suspected drug Etoricoxib was immediately stopped and the patient was managed symptomatically. The Naranjo scale was used to assess the causality of reaction and a score of 7 was obtained, indicating there was a "probable" causal relationship between the suspected drug and the reaction. Severity of the reaction was assessed using Hartwig's severity assessment scale and found out to be a "moderately" severe adverse reaction.
\end{abstract}

Key words: Adverse Drug Reaction, Skin Lesions, Etoricoxib, Epidermal Necrolysis.

\section{INTRODUCTION}

Etoricoxib is a selective Cyclooxygenenase (COX-2) enzyme inhibitor which is used mainly for analgesic effects in various diseases like osteoarthritis, rheumatoid arthritis, gouty arthritis, acute pain which includes postoperative dental pain, ankylosing spondylitis, chronic low back pain, gout etc. ${ }^{1,2,3}$ Although it is highly efficacious in pain management, the safety profile of COX-2 inhibitor is yet not established in a broader sense. ${ }^{4,5}$ The drug is approved in more than 80 countries but not in US because the FDA has asked for additional data for proving safety and efficacy before issuing its approval. Studies have shown various cases of etoricoxib induced pretibial erythema, edema, thrombocytopenia, rashes etc. ${ }^{6}$ Some reported side effects caused due to the drug also include generalized erythema, acute generalized exanthemata's pustulosis, erythema multiform like eruptions, pretibial erythema. The tendency of etoricoxib when used in high doses to increase the side effects or adverse drug reactions to NSAIDS was also reported in most of the cases. ${ }^{7,8}$

\section{CASE REPORT}

A 19 year old male patient was presented with the symptoms of skin rashes over the face, trunk and extremities. Detailed past history suggested that the patient consulted a physician for rheumatoid arthritis for which he has been prescribed with Etoricoxib $60 \mathrm{mg}$ orally. Patient took the medication for nearly 1 month and it was after that maculopapular, erythematous skin rashes associated with itching started developing. The patient was immediately admitted in medicine department and the suspected drug was stopped, as his condition was serious with skin rashes all over the body.

Multiple therapies were prescribed to the patient, hydroxy chloroquine $(200 \mathrm{mg})$ was given every day morning to relieve the symptoms of rheumatoid arthritis. On dermatological consultation Dexamethasone (8 mg) was given intravenously twice a day for 9 days and Tab ciprofloxacin (500mg) twice a day were prescribed along with the liquid paraffin for topical application. Tab Prednisolone $(40 \mathrm{mg})$ was started on the $6^{\text {th }}$
DOI: 10.5530/ijopp.10.3.46

Address for correspondence: Syed Zia Inamdar, Associate Professor \& Clinical Pharmacist, Department of Pharmacy Practice BLDEA's College of Pharmacy, Vijaypur 586103, Karnataka, INDIA.

Phone no: :+91-9986666016 Email Id: syedzia.inamdar@ gmail.com

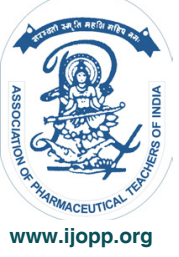




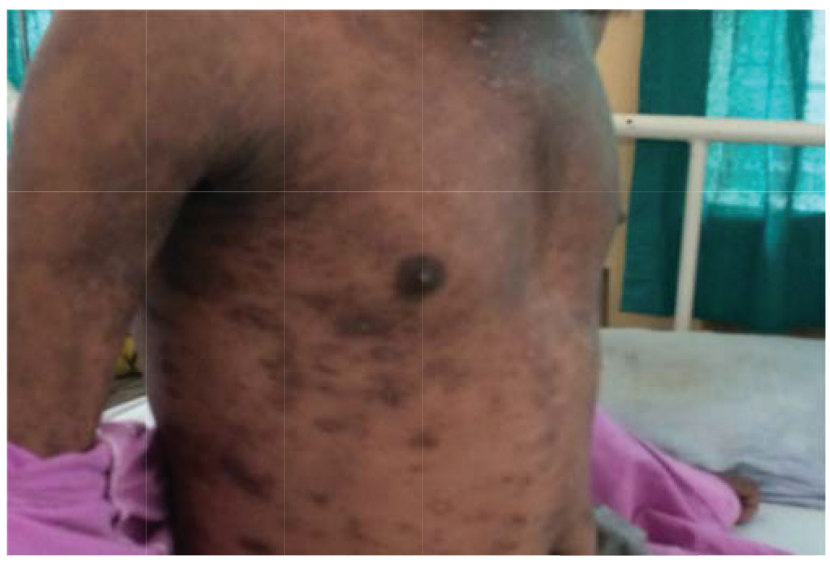

Figure 1: Etoricoxib induced skin rashes [Chest ]

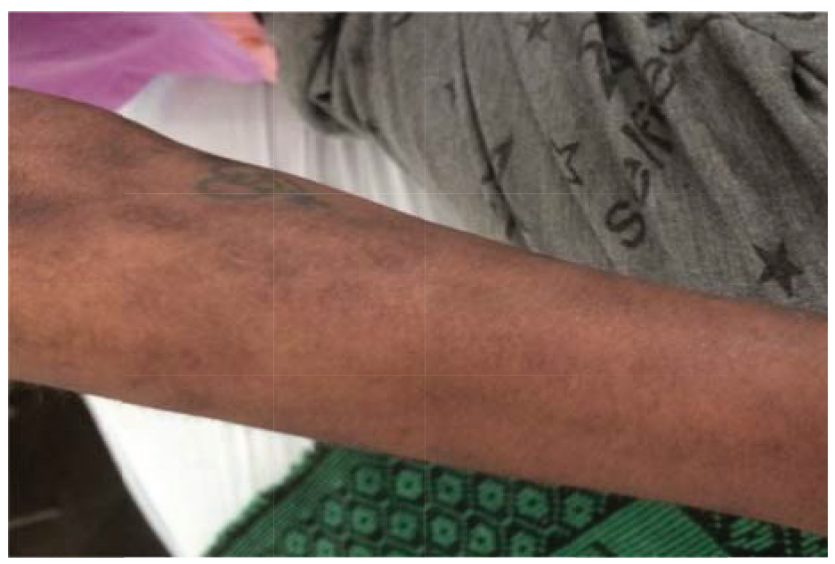

Figure 2: Etoricoxib induced rashes [Right Forearm]

day of treatment and $20 \mathrm{mg}$ of Prednisolone was started on $11^{\text {th }}$ day of treatment along with Indocin $75 \mathrm{mg}$ for the treatment of rheumatoid arthritis. Mometasone topical cream was prescribed for the skin rashes in the chest area Figure1 and 2. On the first day of hospitalization, the laboratory investigation revealed a marginal elevation of ESR-110, polymorphs 81 and decrease in haemoglobin (9.0 mg \%), slight decrease in MCH (27) \& lymphocytes (15). During treatment, the patient developed burning sensation in stomach, restlessness, and difficulties in micturition. The gastro intestinal symptoms were managed symptomatically with histamine 2 receptor blockers and received prophylactic antibiotic. The glucocorticoid doses were tapered appropriately with gradual resolution of the symptoms and the patient was discharged after complete ablation of rashes with proper instructions regarding the possible relapse.

\section{DISCUSSION}

Etoricoxib is a selective COX-2 inhibitor which is used mainly for the treatment of rheumatoid arthritis, psoriatic arthritis, osteoarthritis, ankylosing spondylitis, chronic low back pain, acute pain and gout. It acts by inhibiting cyclo-oxygenase 2 enzyme, which is involved in the production of prostaglandins. Prostaglandin production leads to inflammation and pain. By inhibiting the production of prostaglandins by acting on COX-2, Etoricoxib helps in reducing pain. In the current case the patient was admitted with complaints of skin rashes over the face, trunk \& extremities. While assessing the history it was found that the patient was taking Etoricoxib 60mg daily as per the advice of physician for treating rheumatoid arthritis for almost a month. Immediately Etoricoxib was stopped since his condition was getting worse with skin rashes all over the body. Hydroxy chloroquine was given to treat the symptoms of rheumatoid arthritis after etoricoxib was stopped. Dexamethasone injection $8 \mathrm{mg}$ was prescribed for 9 days. Dexamethasone is a type of corticosteroid medication which is used to treat rheumatoid problems, number of skin diseases, severe allergies etc. Tab ciprofloxacin $500 \mathrm{mg}$ twice a day were prescribed to prevent any type of infections. Tab Prednisolone $40 \mathrm{mg}$ was started on the $6^{\text {th }}$ day of treatment and $20 \mathrm{mg}$ of Prednisolone was started on $11^{\text {th }}$ day of treatment, Prednisolone is a steroid medication used to treat certain type of allergies, inflammatory conditions etc. It was given to treat rashes and allergic reactions. Indocin $75 \mathrm{mg}$ is a NSAID which was prescribed to treat swelling from inflammation and rheumatoid arthritis. Mometasone topical cream was prescribed for the skin rashes in the chest area. The patient condition started getting better after stopping Etoricoxib and the rashes were healed on discharge.

The causality assessment was carried out using Naranjo scale [Table 1]. A total score of 7 was obtained, which indicates that there is a probability that the adverse reaction is caused due to the suspected drug itself. The score of 9 or greater indicates definite, 5 to 8 indicates probable, 1 to 4 indicates possible and 0 indicates doubtful causal relationships.

Hartwig's scale was used to assess the severity of the ADR. According to Hartwig's scale it was found that the ADR occurred was of level 4(which denotes that an ADR which increases the length of hospital stay by at least one day or if the ADR was the reason for the admission), hence the ADR severity falls under level 4 as a moderately severe reaction.

\section{CONCLUSION}

The suspected ADR was found to have "probable" causal relationship between the suspected drug Etoricoxib and the observed adverse drug reaction through Naranjo 
Table 1: Causality Assessment of suspected ADR using Naranjo Scale

\begin{tabular}{|c|c|c|c|c|}
\hline Question & Yes & No & Don't Know/NA & Score* \\
\hline Are there previous conclusive reports on this reaction? & +1 & 0 & 0 & 1 \\
\hline Did the adverse event appear after the suspected drug was administered? & +2 & -1 & 0 & 2 \\
\hline $\begin{array}{l}\text { Did the adverse reaction improve when the drug was discontinued or a specific } \\
\text { antagonist was administered? }\end{array}$ & +1 & 0 & 0 & 1 \\
\hline Did the adverse event reappear when the drug was re-administered? & +2 & 1 & 0 & 0 \\
\hline $\begin{array}{l}\text { Are there alternative causes (other than the drug) that could on their own have } \\
\text { caused the reaction? }\end{array}$ & -1 & 2 & 0 & 2 \\
\hline Did the reaction reappear when a placebo was given? & -1 & 1 & 0 & 0 \\
\hline $\begin{array}{l}\text { Was the drug detected in blood (or other fluids) in concentrations known to be } \\
\text { toxic? }\end{array}$ & +1 & 0 & 0 & 0 \\
\hline $\begin{array}{l}\text { Was the reaction more severe when the dose was increased or less severe } \\
\text { when the dose was decreased? }\end{array}$ & +1 & 0 & 0 & 0 \\
\hline $\begin{array}{l}\text { Did the patient have a similar reaction to the same or similar drugs in any } \\
\text { previous exposure? }\end{array}$ & +1 & 0 & 0 & 0 \\
\hline Was the adverse event confirmed by any objective evidence? & +1 & 0 & 0 & 1 \\
\hline Total Score & & & & 7 \\
\hline
\end{tabular}

*Score: Definite: $\geq 9$, Probable: 5-8, Possible:1-8, Doubtful: 0

Report: The suspected ADR found to be Probable on Naranjo scale assessment.

causality assessment. Severity assessment through Hart wig's scale put the observed ADR under "moderately" severe reaction category. The report suggests close monitoring of Etoricoxib usage among population for the occurrence of ADR.

\section{REFERENCE}

1. Pragnesh A, Saksena M. Adverse drug reactions of non-steroidal antiinflammatory drugs in orthopaedic patients. J Pharmacol Phamacother. 2011;2(1):26-9.

2. Balasingam $\mathrm{N}$, Thirunavukarasu K, Selvaratnam $\mathrm{G}$. Etoricoxib- induced pleural effusion: A case for rational use of analgesics. J Pharmacol Pharmacother. 2015;6(4):231-2.
3. Dhikav V,Singh S, Anand KS. Newer non-steroidal anti- inflammatory drugs: A review of their therapeutic potential and adverse drug reaction. J Indian Acad Commun Med. 2002;3(4):332-8.

4. Lazarou J, Pomeranz BH, Corey PN: Incidence of adverse drug reactions in hospitalized patients: a meta-analysis of prospective studies. Jr Am Med Assoc. 1998;279(15):1200-5.

5. Roy M, Ismael M, Josaine $H$. Etoricoxib induced toxic epidermal necrolysis. International journal of dermatology. 2014;53(4):240-316.

6. Pramod K. Etoricoxib induced pretibial erythema and edema. Indian Dermatol Online J. 2015;6(1): S47-S49.doi: 10.4103/2229-5178.171046

7. Manappallil RG, Krishnan V. A case of wet purpura due to etoricoxib induced thrombocytopenia. Asian J Med Science. 2016;7(5):135-7. DOI: 10.3126/ajms. v7i5. 14674

8. Haag MD, Bos MJ, Hofman A, Koudstaal PJ, Breteler MM, Stricker BH. Cyclooxygenase selectivity of nonsteroidal anti-inflammatory drugs and risk of stroke. Arch Intern Med. 2008;168(11):1219-24. 